\title{
Cross-community congruence of patterns in a marine ecosystem: Do the parts reflect the whole?
}

\author{
I. Karakassis ${ }^{1, *}$, A. Machias ${ }^{2}$, P. Pitta ${ }^{2}$, K. N. Papadopoulou ${ }^{2}$, C. J. Smith ${ }^{2}$, \\ E. T. Apostolaki ${ }^{1,2}$, M. Giannoulaki ${ }^{2}$, D. Koutsoubas ${ }^{3}$, S. Somarakis ${ }^{4}$ \\ ${ }^{1}$ Department of Biology, University of Crete, PO Box 2208, Heraklion 71409, Crete, Greece \\ ${ }^{2}$ Hellenic Centre for Marine Research, PO Box 2214, Heraklion 71003, Crete, Greece \\ ${ }^{3}$ University of Aegean, Department of Marine Science, Mitilini 81100, Greece \\ ${ }^{4}$ University of Patras, Department of Biology, Patras 26500, Greece
}

\begin{abstract}
Cross-community congruence patterns of species diversity metrics and community similarity between macrobenthic infauna, epibenthic megafauna, demersal fish and microzooplankton ciliates were studied in 6 areas in the Eastern Mediterranean. These species-rich communities, cooccurring in space and time, were intensively sampled during 2 cruises, in seasons reflecting different levels of subtle anthropogenic stress. Comparisons of patterns showed high positive correlation of similarities in community structure between macrofauna and megafauna, megafauna and fish and fish and microzooplankton. However, the employed diversity metrics varied between communities, occasionally showing negative correlations. We suggest that the species composition and diversity of these communities reflect different environmental gradients and sources of heterogeneity, and therefore none of them can be used as a surrogate for ecosystem biodiversity in the context of marine conservation planning.
\end{abstract}

KEY WORDS: Macrofauna $\cdot$ Megafauna $\cdot$ Demersal fish $\cdot$ Microzooplankton $\cdot$ Diversity $\cdot$ Community structure

\section{INTRODUCTION}

Margalef (1968) wrote that, 'Diversities have to be computed in segments of the ecosystem. One soon gets the impression that total diversity is almost mythical but that diversity of the ecosystem is reflected with little distortion at several levels, so that if the diversity of phytoplankton is high the diversity of zooplankton and even of pelagic fishes is high also. It is not an exaggeration to say that a look at the fish market allows a first estimate of the diversity of the plankton populations living in the same water'. This is an incisive expression and probably one of the earliest enouncements of the hypothesis that surrogates could be used as a means of assessing biodiversity. During the last decade this statement has been reinvented, restated, and used and tested by several authors since the conceptually straightforward task of managing biodiver- sity is in practice a difficult proposition (MacNally et al. 2002). Flagship, umbrella, and indicator taxa are some of the surrogates suggested for meeting conservation objectives by using single or several species instead of whole biotas, and whichever taxon is used, it is meant to be a surrogate representative of patterns of biodiversity across the study domain (MacNally et al. 2002). The published scientific literature on surrogates includes quite an extensive list of papers from different areas and terrestrial ecosystem types (e.g. Louette \& Bijnens 1995, Faith \& Walker 1996, Lawton et al. 1998, Simberloff 1998, Kitching et al. 2000, Andelman \& Fagan 2000) and a few dealing with the marine environment and particularly with intertidal rocky shores (Gladstone 2002, Gladstone \& Davis 2003). However, the use of surrogate taxa in conservation planning has become suspect, as recent evidence suggests that the correlation of species richness and coincidence of 
diversity 'hotspots' between pairs of taxa is highly variable and may be dependent on the spatial scale examined (Su et al. 2004 and references therein). Few researchers have directly compared patterns of crosstaxon congruency in species richness and community composition, and most of the approaches used have not addressed the congruency of community composition or beta diversity per se (Lawton et al. 1998, MacNally et al. 2002, Su et al. 2004); further, all of them come from the terrestrial environment.

According to Giller et al. (2004), when compared to terrestrial systems, aquatic ecosystems are characterised by greater propagule and material exchange, often steeper physical and chemical gradients, more rapid biological processes and, in marine systems, higher metazoan phylogenetic diversity. These characteristics limit the potential to transfer conclusions derived from terrestrial experiments to aquatic ecosystems, whilst they do provide opportunities for testing the general validity of hypotheses about effects of biodiversity on ecosystem functioning. Furthermore, at present there is a large difference between the spatial scales on which marine biodiversity mapping is possible and the scales at which management decisions need to be made (Olsgard et al. 2003). Authors of many papers discussing progress in research on spatial patterns in taxonomic diversity and/or effects of biodiversity on ecosystem function (e.g. Gaston \& Williams 1996, Gray 2000, Hooper et al. 2005) have expressed their reservation as to whether the knowledge gained from the research in terrestrial ecosystems is also applicable to marine ecosystems.

According to the definition of Krebs (2001), a community is 'any assemblage of populations of living organisms in a prescribed area or habitat'. However, the scientist rarely has the chance of registering all the species in a community or even to sample all the biota, particularly so in the case of marine ecosystems, where remote sampling is the rule. Due to practical shortcomings, species richness more often than not refers to a single taxon, since taxonomic expertise is usually limited to specialisation in a single taxon (Gray 2000). Different sampling methods (e.g. grabs, dredges, trawls) and sample processing configurations (e.g. sieving) provide different data sets which do not necessarily lead to identical results. Olsgard \& Somerfield (2000) and Olsgard et al. (2003) have tested the potential for using 'sub-community' surrogates such as polychaetes to assess the overall diversity and community structure of the macrobenthos. In a few more cases, more than one marine community has been studied and results have been compared (Warwick \& Clarke 1991, Callaway et al. 2002, Lovell \& Trego 2003, Hillebrand 2004, Irigoien et al. 2004, Kaiser et al. 2004) in the particular context of each paper. However, it is still unknown whether a wide range of marine communities from infaunal invertebrates to demersal fish and plankton organisms, co-occurring in space and time, interacting in various ways and at various levels, depending on the same primary production and subject to varying degrees to local disturbance provide similar or different patterns in community structure and species diversity. Furthermore, it has recently been shown (Moustakas \& Karakassis 2005) that aquatic and marine biodiversity research is biased in terms of geographic distribution and taxa studied. This lack of knowledge is a major impediment in the planning of protected marine areas, and particularly so in the case of marine ecosystems with soft sediment seabeds which constitute the largest single ecosystem on earth in terms of spatial coverage (Snelgrove et al. 1997).

The aim of the present paper was to compare univariate and multivariate patterns obtained through the analysis of different marine communities which were not subject to severe environmental pressures such as anoxia or intense physical disturbance. To this end, during 2 cruises, 6 coastal areas in the eastern Mediterranean were sampled for macrobenthic infauna, epibenthic megafauna, demersal ichthyofauna and microzooplankton ciliates. The comparison involved different diversity metrics as well as community structure similarities between all possible pairs of communities. To our knowledge this is the first attempt to carry out such comparisons in the marine environment.

\section{MATERIALS AND METHODS}

The study areas. Macrofauna, megafauna, fish fauna and plankton ciliates were sampled at 3 islands of the Aegean archipelago (Evia, Lesvos and Chios Islands) in the eastern Mediterranean basin. In each region, one sub-area under moderate anthropogenic pressure (i.e. near a zone of fish farming activity) was sampled, as well as one sub-area far away from these zones and any other source of land based anthropogenic pressure (hereafter referred to as 'reference site'). The location near the fish farming zones was no less than 2 nautical miles ( $n$ mile) from the nearest farm since the aim of the survey was to assess the potential meso-scale effects and not the well known effects on communities found in the immediate vicinity of the farms (Weston 1990, Karakassis et al. 1999, 2000). Sampling was carried out during May 2001 and September 2002, the former before the closed period for trawling in Greece and during the reproduction period for most of the commercial fish species (Stergiou et al. 1997), while the latter took place before the open period for trawling and during the recruitment period for most of the 
fish species. Reference sites had comparable topography, depth (70 to $80 \mathrm{~m}$ ) and an average distance of $20 \mathrm{n}$ miles from the respective fish farm sites. In all 6 sites the substrates were mud and sand mixed with maerl in different ratios. For data analysis, the substrates with more than $40 \%$ silt and clay were classified as 'fine' and the others as 'coarse'. Thus, the benthic environment is typical of the fishing grounds exploited in the Mediterranean, and half of the areas were subject to subtle nutrient enrichment from the adjacent fish farming zones as was shown by Pitta et al. (2005). Machias et al. (2005) have provided results on the effects of fish farming zones on fish biomass and included maps of the areas studied.

Sampling design. During each sampling survey, fish fauna were sampled with 3 replicate hauls at each site using an otter trawl with a cod-end bag liner of $28 \mathrm{~mm}$ stretched mesh size. The haul duration ranged between 40 and 45 min with towing speeds between 2.8 and 3 knots. The door spread of the trawl net was calculated for each haul based on the method of Carrothers (1980). In total, 36 hauls were carried out for fish fauna collection during both seasons.

Megafauna was also sampled taking 3 replicate hauls at the same sampling stations during each sampling cruise by means of an Agassiz beam trawl, considered the best method for collecting sparsely distributed megafauna. The $2 \mathrm{~m}$ beam Agassiz trawl was fitted with a $10 \mathrm{~mm}$ mesh bag liner, the tow duration was fixed at 30 min and the towing speed was kept to approximately 1.5 knots. DGPS positions, along with speed and depth, were noted every $5 \mathrm{~min}$ while the Agassiz was on the bottom.

Macrofauna was collected with a Smith-McIntyre grab $\left(0.1 \mathrm{~m}^{2}\right)$, taking at each sub-region and during each survey 10 replicates, randomly distributed over the entire area covered by the above mentioned towed gear.

Plankton ciliates were collected by means of Niskin bottles at 3 sampling stations at each sub-region and during each survey covering the area sampled by the benthic samplers.

Sample processing. Fish specimens and megafauna were identified on board the RV 'Philia'. All macrofauna samples were sieved in situ through a $500 \mu \mathrm{m}$ mesh and the retained sediment containing the macrofauna organisms was preserved in $10 \%$ buffered formalin. Samples were sorted by hand into major groups, and specimens were identified to species level. Samples for microzooplankton (20 to $200 \mu \mathrm{m}$ ) identification and enumeration were preserved with acid Lugol's solution. After $24 \mathrm{~h}$ sedimentation in $100 \mathrm{ml}$ cylinders, the samples were observed under an inverted microscope (Olympus IX-70) according to Utermöhl (1958). Ciliates were identified to species or genus level.
Data analysis. To compare similarities in patterns between different communities, abundance was calculated for each community by averaging all replicates taken during one season in each of the 6 areas and therefore, for each community the data set contained 12 points ( 6 areas $\times 2$ seasons). Various diversity metrics were calculated: number of species per station $(S)$, Margalef's index of species richness $(d)$, Pielou's evenness $\left(J^{\prime}\right)$, the $\log _{2}$ Shannon-Wiener species diversity index $\left(H^{\prime}\right)$, Simpson's dominance $(\lambda)$ as well as the new 'biodiversity indices' $\left(\Delta^{*}, \Delta+, \Lambda+\right)$ based on taxonomic distinctness (Warwick \& Clarke 1995, Clarke \& Warwick 1998). Multivariate analysis of samples taken in each community involved the use of the Bray-Curtis similarity index on 4 th root transformed data. All of these analyses were carried out using PRIMER-5 software (Clarke \& Warwick 1994). Comparisons of multivariate patterns between different communities were carried out by means of analysis of correlation between similarity matrices, using the method described in Somerfield \& Clarke (1995). The non-parametric Spearman rank correlation coefficient was used for all correlations between variables.

\section{RESULTS}

The analysis of samples yielded 438 macrobenthic species, 206 megafaunal species, 83 fish species and 102 species of microplankton ciliates. The multidimensional scaling results for all different communities (Fig. 1) showed that different factors were responsible for the clusters formed in each plot. Fish and ciliates clearly formed clusters according to the sampling season, whereas macrofauna and megafauna stations clustered in response to sediment type rather than any other factor. The silty sediment sites (EN, LF and XN) formed distinct clusters comprising samples from both sampling seasons. On the other hand, proximity to the fish farming zones (marked with $\mathrm{N}$ for near or $\mathrm{F}$ for far in Fig. 1) did not seem to affect the species composition in any of the communities examined in this paper.

The comparison of Bray-Curtis similarities (Fig. 2) between all different pairs of communities revealed only positive relationships, although the ranges of similarity varied considerably between the different communities investigated. Megafauna showed the widest range in terms of similarity between different areas and seasons (11 to $66 \%$ ) with an average similarity of $36 \%$ between all possible pairs of samples. At the other end of the scale, microplankton ciliates showed the narrowest range (62 to $85 \%$ ) with an average of $73 \%$.

The comparison between multivariate patterns obtained for different communities (Table 1) showed that there were highly significant positive similarities $(\mathrm{p}<$ 

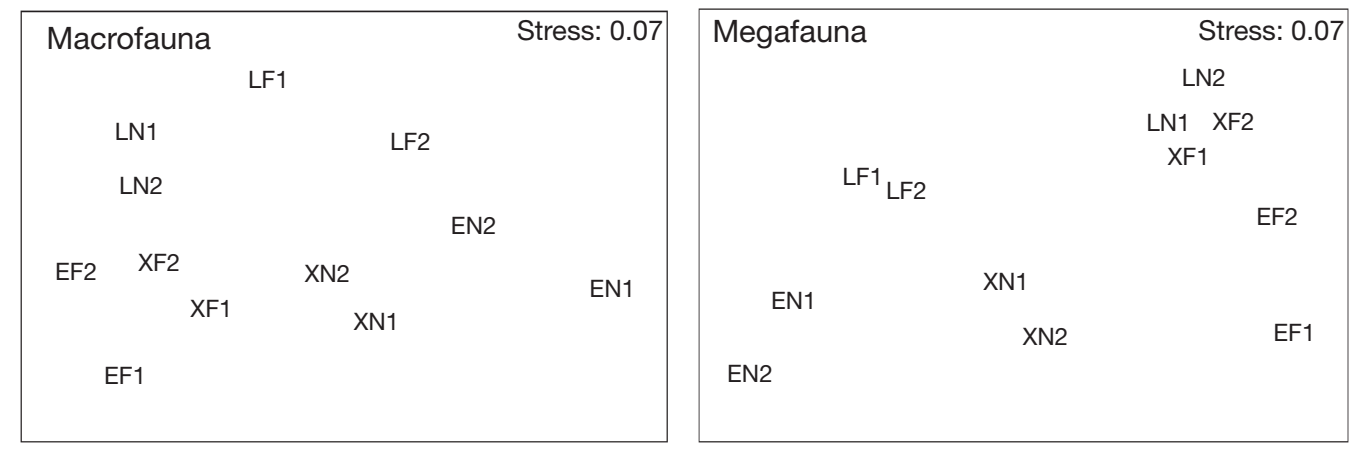

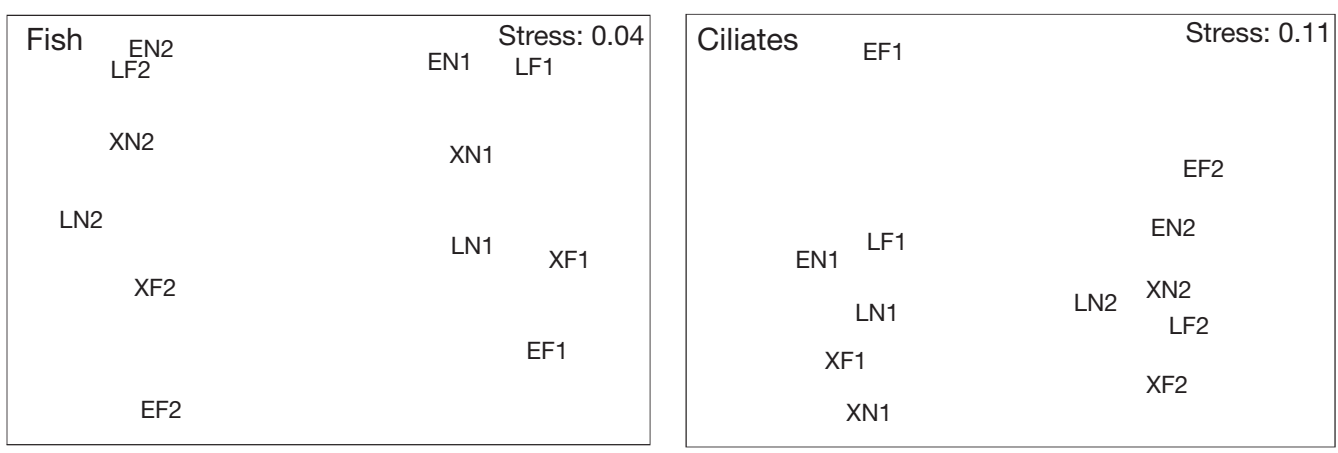

Fig. 1. Multidimensional scaling ordination plots for all communities investigated at 3 islands (E: Evia, L: Lesvos, X: Chios), at 2 distances from the fish farming zones (N: near the fish farming zones, i.e. $>2$ but $<10 \mathrm{n}$ miles; F: far from the fish farming zones, i.e. $>10 \mathrm{n}$ mile) and during 2 sampling cruises (1: May, 2: September)
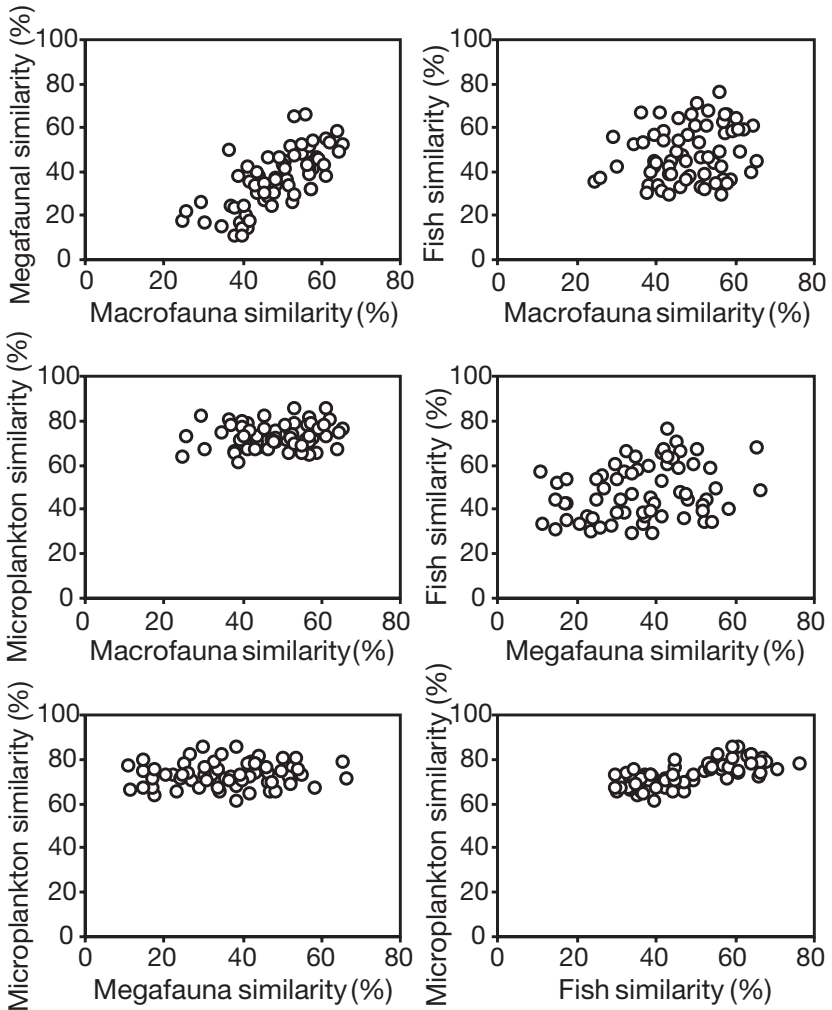

Fig. 2. Cross-community correlations among macrobenthic infauna, epibenthic megafauna, demersal fish and microplankton ciliates; community similarity (Bray-Curtis similarity) between all pairwise combinations of areas sampled
0.0001) between macrofauna and megafauna, between fish fauna and microplankton ciliates, as well as between fish and megafauna (at $\mathrm{p}<0.05$ ), whereas none of the other 3 comparison pairs showed any significant results. The overall comparison between similarity patterns can be seen in a second-stage ordination plot (Fig. 3) showing that the macrofauna and the megafauna were the communities closest to each other in terms of similarity patterns, whereas the community of ciliates is quite different and the fish community is at an intermediate position.

In total, 48 comparisons were carried out between all different pairs of communities and for 8 diversity metrics (Table 2). These comparisons showed only sporadic similarities between communities (9 in total), occasionally showing inverse patterns. It is worth noting that the pairs of communities showing highly significant correlations in multivariate patterns of com-

Table 1. Rank correlation coefficient comparing multivariate patterns obtained for different pairs of co-occurring marine communities. ${ }^{*} \mathrm{p}<0.05,{ }^{* *} \mathrm{p}<0.0001$

\begin{tabular}{|lcll|}
\hline & Megafauna & Fish & Ciliates \\
\hline Macrofauna & $0.71^{* *}$ & 0.22 & 0.18 \\
Megafauna & & $0.27^{*}$ & 0.08 \\
Fish & & & $0.68^{* *}$ \\
\hline
\end{tabular}


Table 2. Correlation coefficients of various diversity metrics among communities. $S$ : number of species per station; $d$ : Margalef's index of species richness: $J^{\prime}$ : Pielou's evenness; $H^{\prime}$ : Shannon-Wiener species diversity index; $\lambda$ : Simpson's dominance: $\Delta^{*},{ }^{*}{ }^{\prime}$ $\Lambda+$ : other new biodiversity indices. * Values significant at $\mathrm{p}<0.05$

\begin{tabular}{|c|c|c|c|c|c|c|c|c|}
\hline Comparison set & $S$ & $d$ & $J^{\prime}$ & $H^{\prime}$ & Simpson $(\lambda)$ & $\Delta^{*}$ & $\Delta+$ & $\Lambda+$ \\
\hline macro-megafauna & 0.51 & 0.53 & $-0.64^{*}$ & 0.25 & -0.18 & 0.28 & 0.12 & 0.38 \\
\hline macrofauna-fish & $-0.70^{*}$ & $-0.63^{*}$ & 0.34 & -0.14 & -0.11 & $0.64^{*}$ & $0.62^{*}$ & -0.44 \\
\hline macrofauna-ciliates & -0.21 & -0.12 & -0.17 & 0.02 & -0.19 & 0.37 & 0.47 & $0.62^{*}$ \\
\hline megafauna-fish & -0.14 & 0.15 & 0.19 & 0.37 & 0.34 & 0.55 & 0.28 & 0.03 \\
\hline megafauna-ciliates & 0.46 & 0.41 & $0.57^{*}$ & $0.60^{*}$ & $0.68^{*}$ & -0.42 & -0.03 & 0.16 \\
\hline fish-ciliates & 0.37 & 0.38 & -0.07 & 0.34 & 0.44 & -0.16 & 0.28 & -0.13 \\
\hline
\end{tabular}

\begin{tabular}{|lc|}
\hline macrofauna & $\begin{array}{c}\text { Stress: } 0 \\
\text { ciliates }\end{array}$ \\
megafauna & \\
& \\
& fish \\
\hline
\end{tabular}

Fig. 3. 'Second-stage' multidimensional scaling ordination plot of intermatrix rank correlation for the 4 communities investigated

munity structure, such as fish-ciliates and megafauna-fish, showed no correlation in terms of any diversity metric, whereas most of the significant correlations were found in the case of macrofauna and fish; 2 of them (total number of species in the samples and Margalef $d$ ) presenting negative correlations and 2 distinctly positive ones $\left(\Delta^{*}\right.$ and $\left.\Delta+\right)$.

\section{DISCUSSION}

Numerous papers have investigated the correlation between community structure or diversity and environmental gradients, particularly after Field et al. (1982) demonstrated the practical use of multivariate tools in the analysis of multispecies marine communities. Various studies ( $>1500$ by May 2004) have identified responses of inter alia macrofauna, megafauna, fish or plankton community structure to environmental gradients such as depth, pollution, physical disturbance and many others, depending on the context of each study and the environmental variables investigated (PRIMER-E 2004, www.pml.ac.uk/primer/ primary-papers.htm). However, de-spite the fact that these communities often co-occur in space and time, they are not all equally sensitive to the same environmental stimuli and anthropogenic disturbance. Our results indicate that not all marine communities showed similar multivariate patterns in terms of species abundance data in the spatio-temporal scales investigated. Half the pairwise comparisons showed no significant correlation and therefore it seems that there is no overall pattern that could be seen in all the biota in the ecosystem. On the other hand, there were some significant correlations between pairs of communities: (1) macrofauna and epibenthic megafauna, which share a close affinity to the sediment type and therefore the multivariate analysis showed clusters in response to this environmental attribute; (2) megafauna and fish which (at least in part) share food resources and are both affected by trawling activities (Jennings et al. 2001); and (3) fish and ciliates which are both affected more than the other 2 communities by water characteristics and seasonal processes, as shown by the analysis of multivariate patterns.

A similar study in the terrestrial environment (Sue et al. 2004) involving all possible comparisons among birds, butterflies and vascular plants in montane meadow habitats showed significantly positive correlations between all different pairs. However, another terrestrial study by MacNally et al. (2002) investigating conformity between tree species, birds, mammals, reptiles, terrestrial invertebrates, and nocturnal flying insects, showed that less than half of the biotic element-ecological vegetation class pairings were coherent. It is expected that this type of comparison of community similarities depends greatly on the scale (Prendergast \& Eversham 1997) and the strength of the gradients involved. For instance, similarities of communities coming from different bio-geographic areas are likely to yield very high values of correlation coefficients just because these reflect changes in species pools of all different types of biota. Steep gradients due for instance to increased anthropogenic stress could also result in high similarities of patterns. However, in cases of subtle effects (as in the present study) where 
natural gradients are driving the community structure, it is unlikely that all biota will conform to the same pattern. This is probably the situation when choosing an area for a marine reserve, where all the options are expected to be in the same region and not subject to high levels of stress by pre-existing anthropogenic activities. As shown by Machias et al. (2005) and Pitta et al. (2005) neither fish farming activity nor fisheries disturbance could explain the variability in the community structure among the sites they investigated, and therefore it would be reasonable to assume that all these sites are probably as 'pristine' as any other in the Aegean archipelago given their distance from the fish farming zones and the relatively small size of the fishing industry.

None of the species diversity metrics used in our study showed consistent results for all the communities investigated, this has also been found in many other studies (Olsgard et al. 2003, Su et al. 2004, and references therein). It seems this was also the case with the recently introduced taxonomic distinctness related measures (Warwick \& Clarke 1995, Clarke \& Warwick 1998), which are designed to take into account the phylogenetic set up of the species and not only species numbers, despite the fact that these measures are sample size independent and have been shown to work remarkably well in many different communities (e.g. Rogers et al. 1999, Warwick et al. 2002), particularly in detecting environmental stress gradients. It is no surprise that some of these metrics showed similar behaviour in detecting (or not) correlation among pairs of communities. For instance the number of species $(S)$ and Margalef's $d$ are very similar ( $d$ is simply $S-1$ divided by the logarithm of abundance), Shannon index $\left(H^{\prime}\right)$ is also used in the numerator for the calculation of evenness $\left(J^{\prime}\right)$ and $\Delta^{*}$ and $\Delta^{+}$are both expressions of taxonomic distinctness.

The different results obtained for the same pair of communities from the comparisons of multivariate patterns and the comparisons of diversity metrics are not a paradox. Patterns of community structure and diversity are responses to environmental gradients, stress and/ or habitat heterogeneity which are factors operating at various spatio-temporal scales. The mechanisms generating observed patterns in taxonomic diversity remain contentious for several reasons (Gaston \& Williams 1996), such as the difficulty to assess the importance of multiple contributing factors which often co-vary in space, the difficulty to integrate mechanisms operating on ecological and evolutionary time scales, and the difficulty to quantify the role of history. Warwick \& Clarke (1991) have also shown that multivariate patterns of meiofauna correlated to those of macrofauna whereas neither diversity indices nor graphical/distributional methods showed any common pattern between the 2 communities. The communities investigated in the present study vary in terms of size, feeding mode, mobility, behaviour and reproduction. Due to these differences, they are likely to differ in sensitivity to stress and to show variable responses to environmental gradients. As has recently been shown in some coastal systems (Worm et al. 2002), the effects of consumers and nutrients on diversity consistently depend on each other, and the direction of their effects and peak diversity shift between sites of low and high productivity. Also, as this is a case of communities linked with predator-prey interactions, it is possible that the effects of disturbing the higher trophic levels (fish) are likely to cascade down the lower trophic levels as shown by Worm \& Myers (2003) for open sea ecosystems.

In cases such as monitoring of pollution and other types of anthropogenic stress, macrofauna and the associated surrogates can be very useful as has been shown in many studies for different types of effects (Warwick 1988, Olsgard et al. 1997, Karakassis \& Hatziyanni 2000, Dauvin et al. 2003). In this particular context, monitoring is designed to detect, for instance, the spatial extent of disturbance using community structure and diversity as a sensitive tool. Although other indicators and methods such as sediment profiling imagery (Karakassis et al 2002) or even total organic carbon (Hyland et al. 2005) can also serve this purpose up to a point, the use of macrobenthos has been established as a monitoring tool for decades despite the high cost. However, in the case of biodiversity studies, for example, mapping or monitoring biodiversity and conservation planning (e.g. site selection for marine reserves), biodiversity assessment is not just a tool but the objective of the study. In this case, the use of surrogates could be questionable (or even meaningless) since the pieces of the puzzle do not necessarily reflect the 'entire picture' of local biodiversity.

Acknowledgements. The authors acknowledge support by the European Commission (Project AQCESS, Contract Q5RS2000-31151) as well as E. Maravelia, L. Pinakis and the captain and the crew of RV 'Philia' for their assistance during the sampling surveys. Comments by R. Warwick and 2 anonymous reviewers on the manuscript are gratefully acknowledged.

\section{LITERATURE CITED}

Andelman SJ, Fagan WF (2005) Unbrellas and flagships: efficient conservation surrogates or expensive mistakes? Proc Natl Acad Sci USA 97:5954-5959

Callaway R, Alsvag J, de Boois I, Cotter J, and 8 others (2002) Diversity and community structure of epibenthic invertebrates and fish in the North Sea. ICES J Mar Sci 59: 1199-1214

Carrothers PJG (1980) Estimation of trawl door spread from wing spread. J Northw Atl Fish Sci 1:81-89 
Clarke KR, Warwick RM (1994) Change in marine communities: an approach to statistical analysis and interpretation. Natural Environment research Council, Plymouth

Clarke KR, Warwick RM (1998) A taxonomic distinctness index and its statistical properties. J Appl Ecol 35:523-531

Dauvin JC, Gomez Gesteira JL, Salvande Fraga M (2003) Taxonomic sufficiency: an overview of its use in the monitoring of sublittoral benthic communities after oil spills. Mar Pollut Bull 46:552-555

Faith D, Walker P (1996) How do indicator groups provide information about the relative biodiversity of different sets of areas?: on hotspots, complementarity and pattern-based approaches. Biodivers Lett 3:18-25

Field JG, Clarke KR, Warwick RM (1982) A practical strategy for analysing multispecies distribution patterns. Mar Ecol Prog Ser 8:37-52

Gaston KJ, Williams PH (1996) Spatial patterns in taxonomic diversity. In: Gaston KJ (ed) Biodiversity: a biology of numbers and difference. Blackwell, Oxford p 202-229

Giller PS, Hillebrand H, Berninger UG, Gessner MO, and 8 others (2004) Biodiversity effects on ecosystem functioning: emerging issues and their experimental test in aquatic environments. Oikos 104:423-436

Gladstone W (2002) The potential value of indicator groups in the selection of marine reserves. Biol Conserv 104: 211-220

Gladstone W, Davis J (2003) Reduced survey intensity and its consequences for marine reserve selection. Biodivers Conserv 12:1525-1536

Gray JS (2000) The measurement of marine species diversity, with an application to the benthic fauna of the Norwegian continental shelf. J Exp Mar Biol Ecol 250:23-49

Hillebrand H (2004) Strength, slope and variability of marine latitudinal gradients Mar Ecol Prog Ser 273:251-267

Hooper DU, Chapin FS, Ewel JJ, Hector A, and 11 others (2005) Effects of biodiversity on ecosystem functioning: a consensus of current knowledge. Ecol Monogr 75:3-35

Hyland J, Balthis L, Karakassis I, Magni P, Petrov A, Shine J, Vestergaard O, Warwick RM (2005) Organic carbon content of sediments as an indicator of stress in the marine benthos. Mar Ecol Prog Ser 295:91-103

Irigoien X, Huisman J, Harris RP (2004) Global biodiversity patterns of marine phytoplankton and zooplankton. Nature 429:863-867

Jennings S, Kaiser MJ, Reynolds JD (2001) Marine fisheries ecology. Blackwell, Oxford

Kaiser MJ, Bergmann M, Hinz H, Galanidi M, Shucksmith R, Rees EIS, Darbyshire T, Ramsay K (2004) Demersal fish and epifauna associated with sandbank habitats. Estuar Coast Shelf Sci 60:445-456

Karakassis I, Hatziyanni E (2000) Benthic disturbance due to fish farming analyzed under different levels of taxonomic resolution. Mar Ecol Prog Ser 203:247-253

Karakassis I, Hatziyanni E, Tsapakis M, Plaiti W (1999) Benthic recovery following cessation of fish farming: a series of successes and catastrophes. Mar Ecol Prog Ser 184: 205-218

Karakassis I, Tsapakis M, Hatziyanni E, Papadopoulou KN, Plaiti W (2000) Impact of cage farming of fish on the seabed in three Mediterranean coastal areas. ICES J Mar Sci 57:1462-1471

Karakassis I, Tsapakis M, Smith CJ, Rumohr H (2002) Fish farming impacts in the Mediterranean studied through sediment profiling imagery. Mar Ecol Prog Ser 227: 125-133

Kitching RL, Orr AG, Thalib L, Mitchell H, Hopkins MS, Graham AW (2000) Moth assemblages as indicators of environmental quality in remnants of upland Australian rain forest. J Appl Ecol 37:284-297

Krebs CJ (2001) Ecology: the experimental analysis of distribution and abundance. Benjamin Cummings, San Francisco, CA

Lawton JH, Bingell DE, Bolton B, Bloemers GF, and 9 others (1998) Biodiversity inventories, indicator taxa and effects of habitat modification in tropical forest. Nature 391:72-76

Louette M, Bijnens L (1995) The utility of birds as bioindicators: case-studies in equatorial Africe. Belg J Zool 125: $157-165$

Lovell LL, Trego KD (2003) The epibenthic megafaunal and benthic infaunal invertebrates of Port Foster, Deception Island (South Shetland Islands,Antarctica). Deep-Sea Res II 50:1799-1819

Machias A, Karakassis I, Somarakis S, Giannoulaki M, Papadopoulou KN, Smith C (2005) The response of demersal fish communities to the presence of fish farms. Mar Ecol Prog Ser 288:241-250

MacNally R, Bennett AF, Brown GW, Lumsden LF, Yen A, Hinkley S, Lillywhite P, Ward D (2002) How well do ecosystem-based planning units represent different components of biodiversity? Ecol Appl 12:900-912

Margalef R (1968) Perspectives in ecological theory. University of Chicago Press, Chicago, IL

Moustakas A, Karakassis I (2005) How diverse is aquatic biodiversity research? Aquat Ecol 39:367-375

Olsgard F, Somerfield PJ (2000) Surrogates in marine benthic investigations - which taxonomic unit to target? J Aquat Ecosyst Stress Recov 7:25-42

Olsgard F, Somerfield PJ, Carr MR (1997) Relationships between taxonomic resolution and data transformations in analyses of a macrobenthic community along an established pollution gradient. Mar Ecol Prog Ser 149: 173-181

Olsgard F, Brattegard T, Holthe T (2003) Polychaetes as surrogates for marine biodiversity: lower taxonomic resolution and indicator groups. Biodivers Conserv 12:1033-1049

Pitta P, Apostolaki ET, Giannoulaki M, Karakassis I (2005) Meso-scale changes in the water column in response to aquaculture zones in three coastal areas in the Eastern Mediterranean Sea. Estuar Coast Shelf Sci 65:501-512

Prendergast JR, Eversham BC (1997) Species richness covariance in higher taxa: empirical tests of the biodiversity indicator concept. Ecography 20:210-216

Rogers SI, Clarke KR, Reynolds JD (1999) The taxonomic distinctness of coastal bottom-dwelling fish communities of the North-east Atlantic. J Anim Ecol 68:658-671

Simberloff D (1998) Flagships, umbrellas, and keystones: Is single-species management passe in the landscape era? Biol Conserv 83:247-257

Snelgrove P, Blackburn TH, Hutchings PA, Alongi DM, and 7 others (1997) The importance of marine sediment biodiversity in ecosystem precesses. Ambio 26:578-583

Somerfield PJ, Clarke KR (1995) Taxonomic levels in marine community studies, revisited. Mar Ecol Prog Ser 127: $113-119$

Stergiou KI, Christou ED, Georgopoulos D, Zenetos A, Souvermezoglou C (1977) The Hellenic seas: physics, chemistry, biology and fisheries. Oceanogr Mar Biol Annu Rev 35:415-538

Su JC, Deminski DM, Jakubauskas ME, Kindscher K (2004) Beyond species richness: community similarity as a measure of cross-taxon congruence for coarse filter conservation. Conserv Biol 18:167-173

Utermöhl H (1958) Zur Vervollkommnung der quantitati- 
ven Phytoplankton-Methodik. Mitt Int Ver Theor Angew Limnol 9:1-38

Warwick RM (1988) The level of taxonomic discrimination required to detect pollution effects on marine benthic communities. Mar Pollut Bull 6:259-268

Warwick RM, Clarke KR (1991) A comparison of some methods for analysing changes in benthic community structure. J Mar Biol Assoc UK 71:225-244

Warwick RM, Clarke KR (1995) New 'biodiversity' measures reveal a decrease in taxonomic distinctness with increasing stress. Mar Ecol Prog Ser 129:301-305

Warwick RM, Ashman CM, Brown AR, Clarke KR and 6 others (2002) Inter-annual changes in the biodiversity

Editorial responsibility: John Gray (Contributing Editor), Oslo, Norway and community structure of the macrobenthos in Tees Bay and the Tees estuary, UK, associated with local and regional environmental events. Mar Ecol Prog Ser 234:1-13

Weston DP (1990) Quantitative examination of macrobenthic community changes along an organic enrichment gradient. Mar Ecol Prog Ser 61:233-244

Worm B, Myers RA (2003) Meta-analysis of cod-shrimp interactions reveals top-down control in oceanic food webs. Ecology 84:162-173

Worm B, Lotze HK, Hillebrand H, Sommer U (2002) Consumer versus resource control of species diversity and ecosystem functioning. Nature 417:848-851

Submitted: March 9, 2005; Accepted: September 21, 2005 Proofs received from author(s): March 3, 2006 